\title{
Urgences
}

\section{Un moment a supporté...}

\section{Danielle Lafontaine}

Numéro 15, octobre 1986

\section{Épigraphiques}

URI : https://id.erudit.org/iderudit/025325ar

DOI : https://doi.org/10.7202/025325ar

Aller au sommaire du numéro

\section{Éditeur(s)}

Urgences

\section{ISSN}

0226-9554 (imprimé)

1927-3924 (numérique)

Découvrir la revue

Citer ce document

Lafontaine, D. (1986). Un moment a supporté... Urgences, (15), 62-62.

https://doi.org/10.7202/025325ar d'utilisation que vous pouvez consulter en ligne.

https://apropos.erudit.org/fr/usagers/politique-dutilisation/ 


\section{Danielle Lafontaine}

Le commencement n'est lisible qu'à la lumiere de la fin.

Claire Lejeune: Le demier testament

Un moment a supporté presque entièrement mon existence. Longtemps j'ai pris plaisir à me savoir capable de me le raconter de manière à éprouver à nouveau cette sorte d'émotion que me cause parfois, depuis, le contact de certaines personnes. J'avais huit ans et je lisais les aventures illustrées de Gazou dans Le petit journal qui paraissait une fois la semaine, le jeudi. J'avais mes raisons pour m'intéresser d'aussi près à cette histoire. Gazou mettait en effet tout en oeuvre pour retrouver sa véritable famille de laquelle, très jeune, il avait été mystérieusement séparé alors que je recherchais moi-même depuis longtemps un enfant disparu encore bébé et auquel j'attribuai, peu à peu, au fil des semaines de lecture, le visage de Gazou. Même durant ces années où j'ai cherché avec obstination à ne vivre qu'au présent, j'ai persisté à me souvenir de cette fois où j'ai pensé reconnaître Gazou. Accroupie dans la poussière entre les deux escaliers de fer, cachée pour regarder des enfants inconnus s'activer dans la lumière encore chaude, rose, du soleil d'été, je m'étais d'abord rendu compte que le trottoir faiblement lézardé de cette rue étrangère et interdite, scintillait en face de moi plus qu'aucun autre examiné auparavant et qu'il n'y avait pas en cet endroit de vent pour me déplacer les cheveux et me les répandre dans le cou. Je savourais encore ces quelques instants inattendus de vraies vacances lorsque je la vis. Plus au sud, la petite s'exerçait à sauter à la corde et toute son histoire, encore inscrite sur son visage signé, défila comme en panorama dans mon cerveau: le bruit, l'alarme, la précipitation. J'eus alors la double certitude d'être arrivée à temps et d'avoir le temps. Je me revois distinguant de loin ses yeux clairs et les contours de ses joues rebondies. Je la sus orpheline avant qu'elle ne se décide à me le dire, bien après m'avoir elle-même voulue comme amie. C'était avant qu'à neuf ans je ne devienne myope de l'avoir trop attendue dans la neige. Avant le ciel. Avant l'enfer. Son énigme s'est imposée de manière obsédante à mon attention pour que je fasse ainsi mon entrée dans le monde.

Toi tu ne savais presque rien de moi lorsque après avoir tout haut noté que je n'avais qu'un seul gant de laine noir, tu me remis son livre qu'elle t'avait chargée de remettre "à la première personne à se manifester". Tu te préparais à partir pour Matane, fêter Noël, mardi, avec les tiens. J'étais arrivée de Rimouski la veille, le vingt décembre, guettant sans succès les signes de "la tempête du siècle" annoncée par André. 